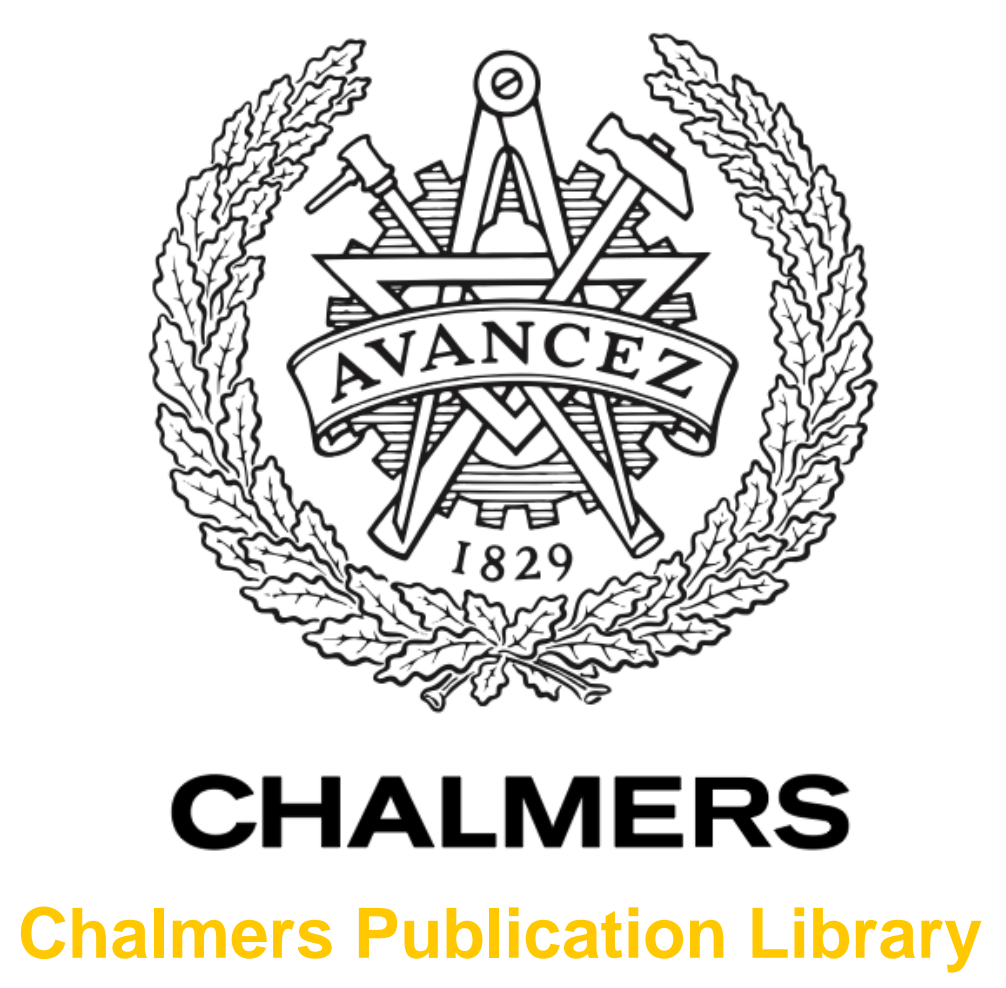

\title{
Towards the chemical control of molecular packing: syntheses and crystal structures of three trans-[NiL4(NCS)2] complexes
}

This document has been downloaded from Chalmers Publication Library (CPL). It is the author's version of a work that was accepted for publication in:

\section{Acta crystallographica Section B, Structural science, crystal engineering and materials}

(ISSN: 2052-5192)

Citation for the published paper:

Soliman, S. ; Elzawy, Z. ; Abu-Youssef, M. (2014) "Towards the chemical control of molecular packing: syntheses and crystal structures of three trans-[NiL4(NCS)2] complexes". Acta crystallographica Section B, Structural science, crystal engineering and materials, vol. 70(1), pp. 115-125.

http://dx.doi.org/10.1107/S2052520613034665

Downloaded from: http://publications.lib.chalmers.se/publication/192750

Notice: Changes introduced as a result of publishing processes such as copy-editing and formatting may not be reflected in this document. For a definitive version of this work, please refer to the published source. Please note that access to the published version might require a subscription. 


\title{
Towards the chemical control of molecular packing: syntheses and crystal structures of three trans-[Ni $\left.L_{4}(\mathrm{NCS})_{2}\right]$ complexes
}

\author{
Saied M. Soliman, Zahia B. Elzawy, Morsy A. M. Abu-Youssef, Jörg \\ Albering, Karl Gatterer, Lars Öhrström and Sidney F. A. Kettle
}

Acta Cryst. (2014). B70, 115-125

Copyright (C) International Union of Crystallography

Author(s) of this paper may load this reprint on their own web site or institutional repository provided that this cover page is retained. Republication of this article or its storage in electronic databases other than as specified above is not permitted without prior permission in writing from the IUCr.

For further information see http://journals.iucr.org/services/authorrights.html

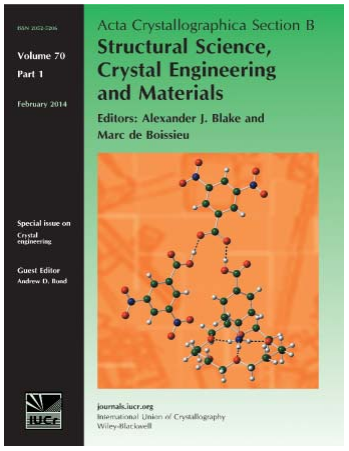

Acta Crystallographica Section B: Structural Science, Crystal Engineering and Materials publishes scientific articles related to the structural science of compounds and materials in the widest sense. Knowledge of the arrangements of atoms, including their temporal variations and dependencies on temperature and pressure, is often the key to understanding physical and chemical phenomena and is crucial for the design of new materials and supramolecular devices. Acta Crystallographica $B$ is the forum for the publication of such contributions. Scientific developments based on experimental studies as well as those based on theoretical approaches, including crystal-structure prediction, structureproperty relations and the use of databases of crystal structures, are published.

Crystallography Journals Online is available from journals.iucr.org 
Acta Crystallographica Section B

Structural Science, Crystal Engineering and Materials

ISSN 2052-5206

Saied M. Soliman, ${ }^{\mathrm{a} *}$ Zahia B. Elzawy, ${ }^{a}$ Morsy A. M. AbuYoussef, ${ }^{a}$ Jörg Albering, ${ }^{\text {b }}$ Karl Gatterer, $^{c}$ Lars Öhrström ${ }^{\mathrm{d} *}$ and Sidney F. A. Kettle

${ }^{\mathrm{a}}$ Chemistry Department, Alexandria University, PO Box 426 Ibrahimia, Alexandria 21321, Egypt, ${ }^{\mathbf{b}}$ Institute of Chemical Technology of Materials, Graz University of Technology, A8010 Graz, Austria, 'Institute of Physical and Theoretical Chemistry, Graz University of Technology, A-8010 Graz, Austria, 'Chemical and Biological Engineering, Chalmers Tekniska Högskola, SE-41296 Gothenburg, Sweden, and ${ }^{\mathbf{e}}$ School of Chemistry, University of East Anglia, Norwich NR4 7TJ, England

Correspondence e-mail: saied1soliman@yahoo.com, ohrstrom@chalmers.se

\section{Towards the chemical control of molecular packing: syntheses and crystal structures of three trans-[NiL $\left.{ }_{4}(\mathrm{NCS})_{2}\right]$ complexes}

Three nickel(II) isothiocyanato complexes of the formula trans-[Ni $\left.L_{4}(\mathrm{NCS})_{2}\right]$ ( $L=$ ethylisonicotinate, methylisonicotinate and 4-benzoylpyridine) have been prepared: [Ni(ethylisonicotinate $\left.)_{4}(\mathrm{NCS})_{2}\right](\mathrm{I}),\left[\mathrm{Ni}(\text { methylisonicotinate })_{4}(\mathrm{NCS})_{2}\right]$ (II) and [Ni(4-benzoylpyridine $\left.)_{4}(\mathrm{NCS})_{2}\right]$ (III). All three complexes are monomeric and have a distorted octahedral geometry around $\mathrm{Ni}^{\mathrm{II}}$. Despite their apparent molecular similarity, the crystal density of (III) $\left(1.454 \mathrm{~g} \mathrm{~cm}^{-3}\right)$ is significantly higher than that of (I) and (II) (both $1.408 \mathrm{~g} \mathrm{~cm}^{-3}$ ), suggesting that the molecular packing is most efficient in (III). A study of the molecular Hirshfeld surfaces, together with density functional theory (DFT) calculations, provide insights into the origin of the molecular packing features, and it is suggested that the greater crystal density of (III) results from smaller intermolecular electrostatic repulsions.

\section{Introduction}

In metal complexes, the thiocyanate group is an ambidentate ligand; it can be an $\mathrm{N}$-donor, an $S$-donor or a bridging $N, S$ ligand. The factors influencing terminal $N$ - or $S$-coordination have received much attention (Burmeister, 1975, 1990). Soft base $S$-coordination appears to be most common for secondand third-row transition-metal ions of soft acid character. In contrast, there appears to be no report of terminal $S$-coordinated thiocyanate with a first-row transition-metal ion such as $\mathrm{Ni}^{\mathrm{II}}$, which is the subject of the present study. A question that arises is whether it is possible to use variations in the other ligands to tune the characteristics of the $\mathrm{Ni}^{\mathrm{II}}$ ion so that thiocyanate becomes $S$-coordinated. Whilst this was the motivation for the present work, the outcome was quite unexpected: we did not change the mode of thiocyanate coordination, but the chemical variations that we introduced had a major influence on the molecular packing in the crystal.

Nickel(II) thiocyanate complexes with $\mathrm{N}$-donor ligands are of interest for several, often related, reasons. Noteworthy are their ability to occur in cis and trans isomeric forms (Đaković et al., 2011), the existence of coordination polymers in which thiocyanate is a linear bridging ligand (Quan et al., 2009) and their potential for development as optical, porous, electrical, magnetic or conductive materials (Fafarman et al., 2011; Zhang et al., 1999; Soldatov et al., 2004; Sinha \& Singh, 2004). Particularly relevant to the present work is that nickel(II) thiocyanate complexes have the details of their crystal architectures controlled by relatively weak forces such as hydrogen bonding (Đaković et al., 2008) or $\pi-\pi$ stacking interactions. These aspects are evident in the crystal structures of nickel(II) isothiocyanate complexes with pyridine, $\gamma$-picoline and nico-
Received 16 September 2013 Accepted 27 December 2013 
Table 1

Experimental details.

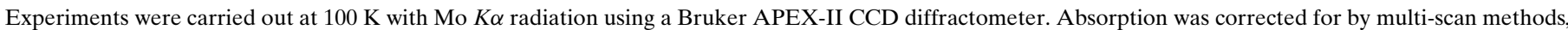
$S A D A B S$ (Bruker, 2008). H-atom parameters were constrained.

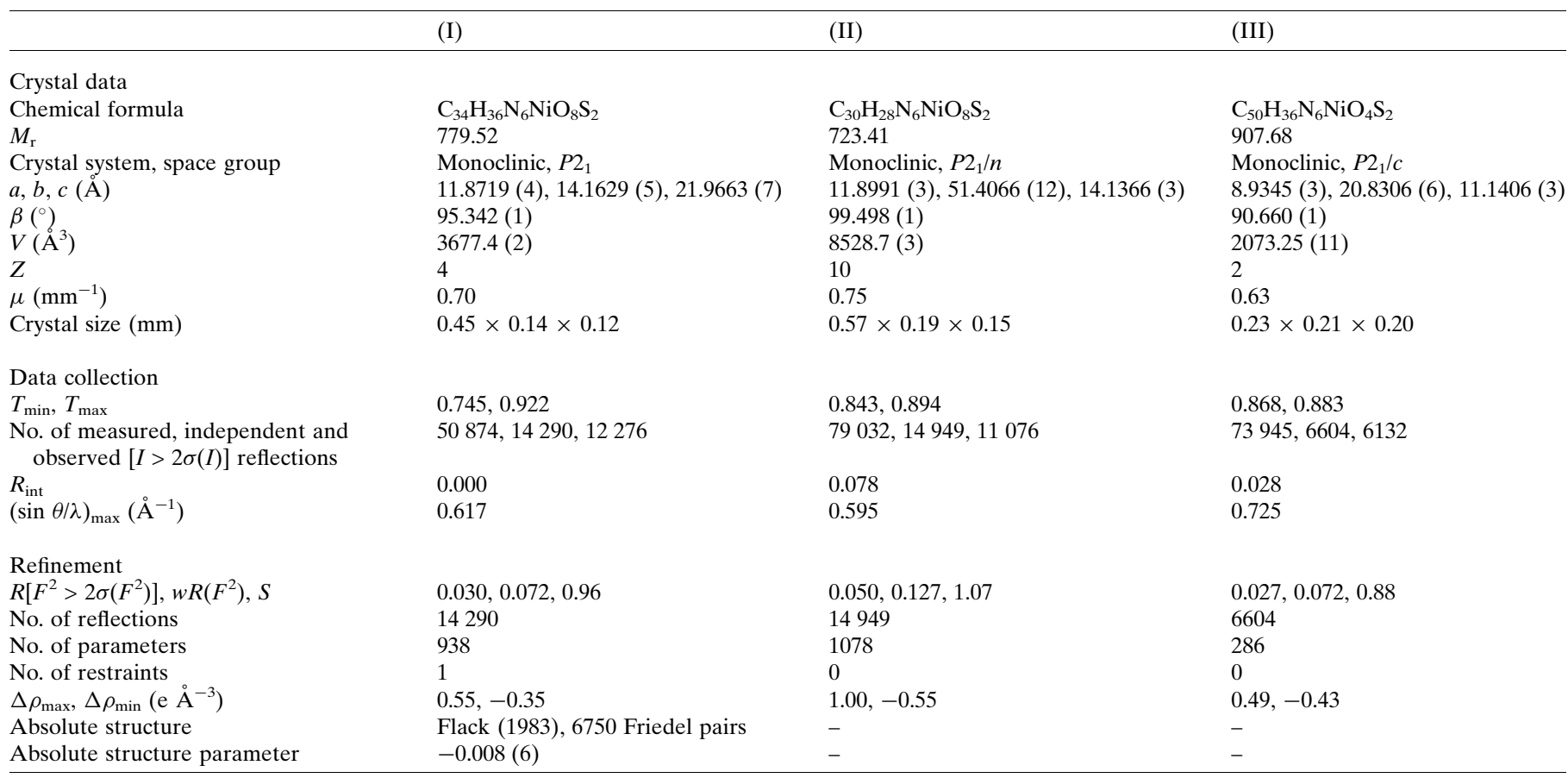

Computer programs: APEX2, SAINT, SHELXTL (Bruker, 2008), SAINT, SHELXS97, SHELXL97 (Sheldrick, 2008).

tinic acid (Đaković et al., 2008, 2011; Wang et al., 2006; Saber et al., 2012; Goher et al., 2003).<smiles>CCOC(=O)c1ccncc1</smiles>

ethylisonicotinate<smiles>COC(=O)c1ccncc1</smiles>

methylisonicotinate<smiles>O=C(c1ccccc1)c1ccncc1</smiles>

4-benzoylpyridine

In the study of nickel(II) thiocyanate complexes for electrical, magnetic and conductive applications, it is inevitable that the focus should be on molecular design. However, the target properties are as much those of the solid-state materials as of the molecules, and so the interactions between molecules, and the consequent molecular packing, becomes relevant. Some aspects of this have already been recognized, as indicated above. Even so, there seems to have been no suggestion that it may be possible to design molecules to explore this important area. Here, we report the synthesis and crystal structures of three new monomeric trans-[Ni $\left.L_{4}(\mathrm{NCS})_{2}\right]$ complexes, with $L=$ ethylisonicotinate (I), methylisonicotinate (II) and 4-benzoylpyridine (III). The somewhat surprising structures obtained are correlated with their spectroscopic and thermal characteristics. Analysis of Hirshfeld surfaces, and some DFT calculations, are also used to gain insight.

\section{Experimental}

\subsection{Materials}

High purity ethylisonicotinate, methylisonicotinate and 4benzoylpyridine were purchased from Aldrich Chemical Company Inc., and used as received. All other chemicals used were of AR grade.

\subsection{Synthesis}

All complexes were prepared by mixing $\mathrm{Ni}\left(\mathrm{NO}_{3}\right)_{2} \cdot 6 \mathrm{H}_{2} \mathrm{O}$ $(1 \mathrm{mmol}, 0.291 \mathrm{~g})$ in $10 \mathrm{ml}$ of distilled water with $4 \mathrm{mmol}$ ethanolic solution of the appropriate ligand followed by addition of a concentrated aqueous solution of KSCN with continuous stirring. The final mixture was allowed to stand for several days at room temperature, giving blue crystals of each complex. The crystals were filtered, washed with 1:10 water:ethanol solution and then air dried. Yield of [Ni(ethylisonicotinate $\left.)_{4}(\mathrm{NCS})_{2}\right]$ (I) $88 \%,\left[\mathrm{Ni}(\text { methylisonicotinate })_{4^{-}}\right.$ $(\mathrm{NCS})_{2}$ ] (II) $85 \%$ and [Ni(4-benzoylpyridine $\left.)_{4}(\mathrm{NCS})_{2}\right]$ (III) $81 \%$. Elemental analysis (\%): $\mathrm{C}_{34} \mathrm{H}_{36} \mathrm{~N}_{6} \mathrm{NiO}_{8} \mathrm{~S}_{2}$ (I): calc.: $\mathrm{C}$ 53.88, H 4.66, N 10.78, S 8.23, Ni 7.53; found: C 53.97, H 4.50, N 10.80, S 8.44, Ni 7.50. $\mathrm{C}_{30} \mathrm{H}_{28} \mathrm{~N}_{6} \mathrm{NiO}_{8} \mathrm{~S}_{2}$ (II): calc.: $\mathrm{C} 49.76, \mathrm{H}$ 3.90, N 11.62, S 8.86, Ni 8.11; found: C 49.72, H 3.84, N 11.58, S 8.91, Ni 8.0. $\mathrm{C}_{50} \mathrm{H}_{36} \mathrm{~N}_{6} \mathrm{NiO}_{4} \mathrm{~S}_{2}$ (III): calc.: C 66.25, H 3.78, N 9.28, S 7.08, Ni 6.48; found: C 66.36, H 3.71, N 9.26, S 7.03, Ni 6.49 . 


\subsection{Physical measurements}

Elemental analyses (CHNS) were performed using a Perkin-Elmer analyser at the Microanalytical Center of Cairo University. The $\mathrm{Ni}^{\mathrm{II}}$ content was determined using a PerkinElmer atomic absorption spectrophotometer at the Faculty of Science of Alexandria University. IR spectra were recorded on a Bruker IFS-125 model FT-IR spectrophotometer, with the samples as $\mathrm{KBr}$ pellets, in the range $400-4000 \mathrm{~cm}^{-1}$. Thermal analyses were performed at the Microanalytical Center of Cairo University, using a Shimadzu thermogravimetric analyser TGA-50H, with the percentage weight loss measured over the range $298-1073 \mathrm{~K}$.

\subsection{X-ray diffraction analysis}

Crystallographic measurements were made using a Bruker Kappa APEX-II $4 \mathrm{~K}$ CCD diffractometer with graphitemonochromated Mo $K \alpha$ radiation at $100 \mathrm{~K}$. H atoms were located in difference Fourier maps or placed at calculated positions and refined as riding with $U_{\text {eq }}(\mathrm{H})=1.2 U_{\text {eq }}(\mathrm{C})$. The

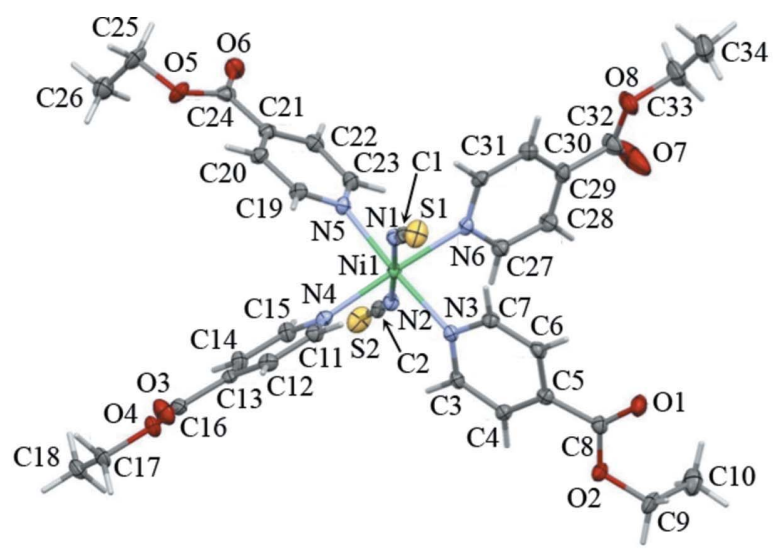

(a)

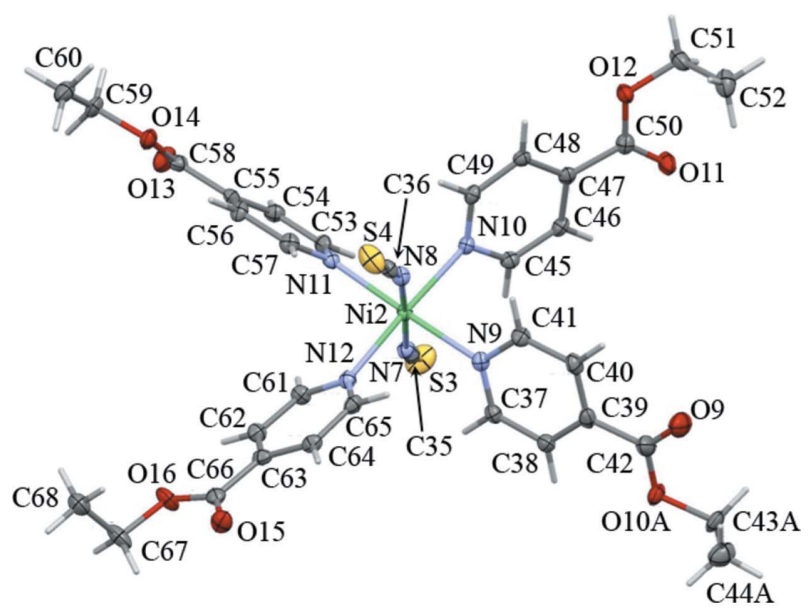

(b)

\section{Figure 1}

Structure and atom-numbering scheme for the two complexes in the asymmetric unit of (I). Displacement ellipsoids are drawn at $50 \%$ probability for non- $\mathrm{H}$ atoms. For the $\mathrm{Ni} 2$ complex, only the major disorder component is shown for $\mathrm{O} 10 A / \mathrm{C} 43 A / \mathrm{C} 44 A$.
Table 2

Comparison of bond lengths $(\AA)$ and angles $\left(^{\circ}\right)$ from the X-ray crystal structure and DFT calculations for the Ni1 complex in (I).

The other complex in the asymmetric unit has comparable geometry. A complete table is given in the supporting information.

\begin{tabular}{lcrlrr}
\hline & Experimental & DFT & & Experimental & DFT \\
\hline Ni1-N1 & $2.033(2)$ & 2.020 & N2-Ni1-N5 & $87.83(7)$ & 90.0 \\
Ni1-N2 & $2.058(2)$ & 2.018 & N6-Ni1-N5 & $91.56(7)$ & 89.8 \\
Ni1-N6 & $2.1205(19)$ & 2.172 & N1-Ni1-N4 & $89.14(7)$ & 90.3 \\
Ni1-N5 & $2.1270(18)$ & 2.172 & N2-Ni1-N4 & $90.18(8)$ & 90.1 \\
Ni1-N4 & $2.1379(19)$ & 2.166 & N6-Ni1-N4 & $177.52(8)$ & 179.9 \\
Ni1-N3 & $2.1494(18)$ & 2.169 & N5-Ni1-N4 & $90.92(7)$ & 90.1 \\
& & & N1-Ni1-N3 & $91.36(7)$ & 89.8 \\
N1-Ni1-N2 & $177.31(8)$ & 179.5 & N2-Ni1-N3 & $91.27(7)$ & 90.0 \\
N1-Ni1-N6 & $90.79(8)$ & 89.7 & N6-Ni1-N3 & $84.43(7)$ & 89.9 \\
N2-Ni1-N6 & $90.00(7)$ & 89.9 & N5-Ni1-N3 & $175.89(7)$ & 179.7 \\
N1-Ni1-N5 & $89.58(7)$ & 90.2 & N4-Ni1-N3 & $93.09(7)$ & 90.2 \\
\hline
\end{tabular}

Table 3

Comparison of bond lengths $(\AA)$ and angles $\left(^{\circ}\right)$ from the X-ray crystal structure and DFT calculations for the Ni1 complex in (II).

The other two complexes in the asymmetric unit have comparable geometry. A complete table is given in the supporting information.

\begin{tabular}{lcrlrr}
\hline & Experimental & DFT & & Experimental & DFT \\
\hline Ni1-N2 & $2.042(3)$ & 2.017 & N1-Ni1-N5 & $90.11(11)$ & 89.9 \\
Ni1-N1 & $2.060(3)$ & 2.019 & N4-Ni1-N5 & $93.72(11)$ & 90.0 \\
Ni1-N4 & $2.112(3)$ & 2.171 & N2-Ni1-N6 & $92.05(11)$ & 90.3 \\
Ni1-N5 & $2.133(3)$ & 2.172 & N1-Ni1-N6 & $90.04(11)$ & 90.1 \\
Ni1-N6 & $2.139(3)$ & 2.170 & N4-Ni1-N6 & $177.65(11)$ & 179.9 \\
Ni1-N3 & $2.154(3)$ & 2.171 & N5-Ni1-N6 & $86.49(11)$ & 90.1 \\
& & & N2-Ni1-N3 & $89.31(11)$ & 89.8 \\
N2-Ni1-N1 & $177.90(11)$ & 179.8 & N1-Ni1-N3 & $90.87(11)$ & 90.1 \\
N2-Ni1-N4 & $90.28(11)$ & 89.8 & N4-Ni1-N3 & $93.19(10)$ & 90.0 \\
N1-Ni1-N4 & $87.62(11)$ & 90.0 & N5-Ni1-N3 & $173.06(10)$ & 179.9 \\
N2-Ni1-N5 & $89.97(11)$ & 90.1 & N6-Ni1-N3 & $86.63(11)$ & 90.0 \\
\hline
\end{tabular}

crystallographic data and refinement details are listed in Table 1.

\section{Results and discussion}

\subsection{Description of the structures}

The structures of (I), (II) and (III) with atom numbering are shown in Figs. 1-3. All of the complexes contain pseudooctahedrally coordinated $\mathrm{Ni}^{\mathrm{II}}$, and there is no bridging between individual molecules. Selected bond distances and angles are listed in Tables 2-4.

\subsection{Crystal structure of $\left[\mathrm{Ni}(\text { ethylisonicotinate })_{4}(\mathrm{NCS})_{2}\right](\mathrm{I})$}

Compound (I) crystallizes in the non-centrosymmetric space group $P 2_{1}$. The principal structural features are illustrated in Fig. 1 and detailed in Table 2. The structure contains two complexes of the formula [Ni(ethylisonicotinate $\left.)_{4}(\mathrm{NCS})_{2}\right]$ in the asymmetric unit, both occupying general positions $\left(Z^{\prime}=\right.$ $2)$. The two complexes differ only very slightly in their $\mathrm{Ni}-\mathrm{N}$

\footnotetext{
${ }^{\mathbf{1}}$ Supporting information for this paper is available from the IUCr electronic archives (Reference: BI5029).
} 
bond distances, and the $\mathrm{N}-\mathrm{Ni}-\mathrm{N}$ bond angles are within a few standard deviations (Table 2). One ethyl group of the ligands around the $\mathrm{Ni} 2$ atom is modelled as disordered, while the remainder of the structure is ordered. The two complexes

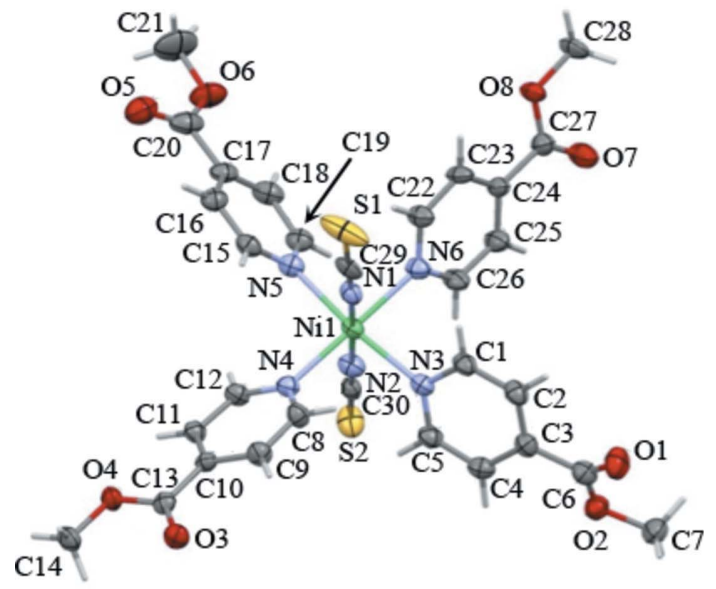

(a)

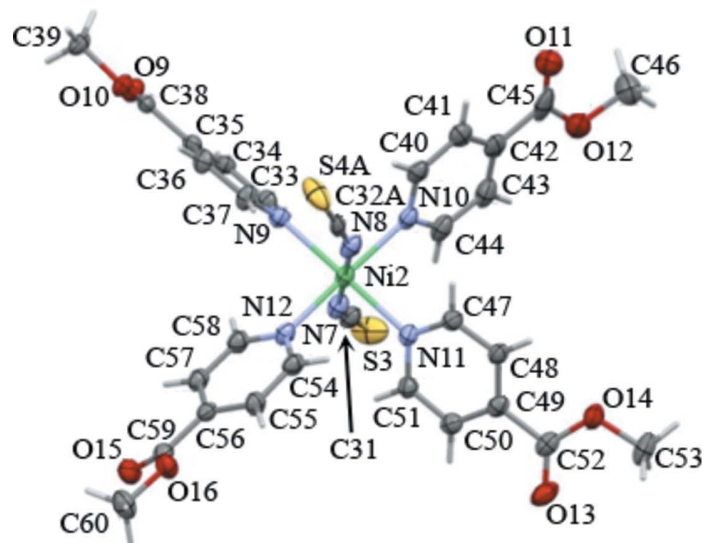

(b)

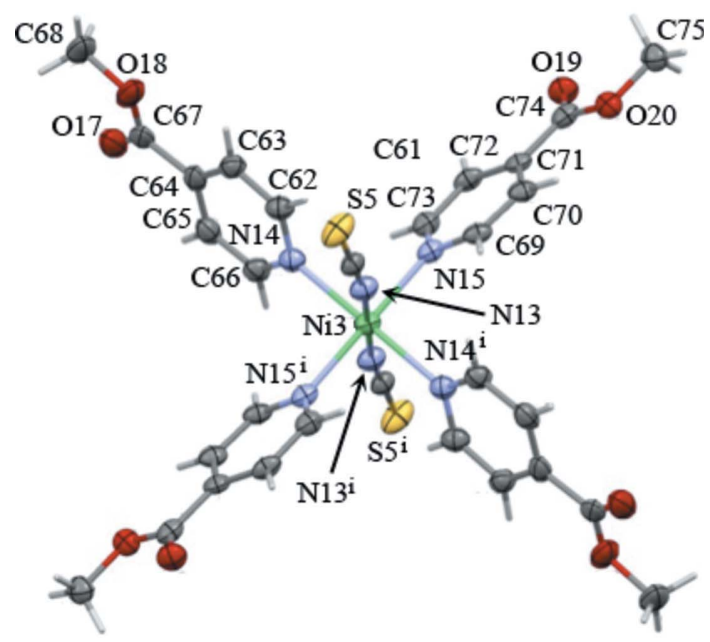

(c)

Figure 2

Structure and atom-numbering scheme for the three complexes in the asymmetric unit of (II). Displacement ellipsoids are drawn at $50 \%$ probability for non-H atoms and only the major component (S4A/C $32 A)$ of the disordered SCN group is shown for the Ni2 complex. The Ni3 complex lies on an inversion centre. Symmetry code: (i) $-x+1,-y,-z+1$.
Table 4

Comparison of bond lengths $(\AA)$ and angles $\left(^{\circ}\right)$ from the X-ray crystal structure and DFT calculations for (III)

\begin{tabular}{|c|c|c|c|c|c|}
\hline & Experimental & $\mathrm{DFT} \dagger$ & & Experimental & DFT $\dagger$ \\
\hline $\mathrm{Ni1}-\mathrm{N} 1$ & $2.0459(8)$ & 1.9898 & $\mathrm{~N} 1{ }^{\mathrm{i}}-\mathrm{Ni} 1-\mathrm{N} 3$ & 89.08 (3) & 88.55 \\
\hline $\mathrm{Ni1}-\mathrm{N} 2$ & 2.1613 & 2.1973 & $\mathrm{~N} 1-\mathrm{Ni} 1-\mathrm{N} 3$ & $90.92(3)$ & 91.45 \\
\hline Ni1-N3 & $2.1613(8)$ & 2.1513 & $\mathrm{~N} 1-\mathrm{Ni} 1-\mathrm{N} 2$ & $89.77(3)$ & 89.95 \\
\hline $\mathrm{N} 1-\mathrm{N} 11-\mathrm{N} 1^{\mathrm{i}}$ & 180 & 180 & $\mathrm{~N} 1{ }^{\mathrm{i}}-\mathrm{Ni} 1-\mathrm{N} 2$ & $90.23(3)$ & 90.05 \\
\hline $\mathrm{N} 3-\mathrm{Ni} 1-\mathrm{N} 3^{\mathrm{i}}$ & 180 & 180 & $\mathrm{~N} 3^{\mathrm{i}}-\mathrm{Ni} 1-\mathrm{N} 2$ & $91.10(3)$ & 89.55 \\
\hline $\mathrm{N} 2-\mathrm{Ni} 1-\mathrm{N} 2^{\mathrm{i}}$ & 180 & 180 & $\mathrm{~N} 3-\mathrm{Ni} 1-\mathrm{N} 2$ & $88.89(3)$ & 90.45 \\
\hline
\end{tabular}

in the asymmetric unit are almost identical, leading to a $Z^{\prime}=2$ superstructure with a $c$ axis of $\sim 22 \AA$, instead of a $Z^{\prime}=1$ substructure with a $c$ axis of $\sim 11 \AA$. It is possible to refine the structure with the same symmetry, halved $c$ axis and one molecular unit in the asymmetric unit, but in this case the disorder found in only one complex in the superstructure is ascribed to both complexes, averaged in the substructure setting. The presence of numerous sharp superstructure reflections with odd $l$ demonstrate clearly that the crystal structure should be described with the larger unit cell. A comparison of the $R_{1}$ values for reflections with even or odd $l$ reveal a value of 0.027 for even $l$, and a higher, but still reasonable, value of 0.087 for the superstructure reflections with odd $l$. It is well known from the literature that structures with $Z^{\prime}>1$ may arise due to pseudo-symmetry effects caused by very similar, but not identical molecular units or atomic arrangements (Gavezzotti, 2008).

In each complex the $\mathrm{Ni}^{\mathrm{II}}$ atom is coordinated by four ethylisonicotinate ligands, with the coordinated $\mathrm{N}$ atoms forming a square-planar arrangement. The $\mathrm{Ni}-\mathrm{N}$ distances range from $2.1205(19)(\mathrm{Ni1}-\mathrm{N} 6)$ to 2.1494 (18) $\AA$ (Ni1$\mathrm{N} 3$ ), while the $\mathrm{N}-\mathrm{Ni}-\mathrm{N}$ bond angles range from 84.43 (7) to $93.09(7)^{\circ} \quad$ (cis) and $175.89(7)$ to $177.52(8)^{\circ}$ (trans). Completing the pseudo-octahedral coordination, there are two thiocyanate ligands in a trans arrangement, coordinated through their $\mathrm{N}$ atoms $(\mathrm{N} 1 / \mathrm{N} 2$ and $\mathrm{N} 7 / \mathrm{N} 8)$ with $\mathrm{N}-\mathrm{Ni}-\mathrm{N}$

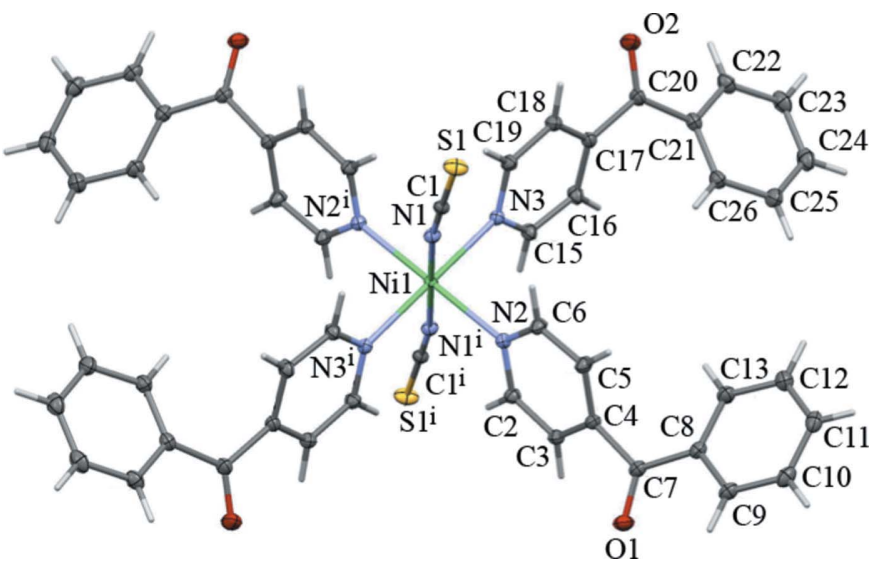

Figure 3

Structure and atom-numbering scheme for (III). Displacement ellipsoids are drawn at $50 \%$ probability for non- $\mathrm{H}$ atoms. The complex lies on an inversion centre. Symmetry code: (i) $-x+1,-y+1,-z+1$. 
bond angles of $177.31(8)$ and $177.68(8)^{\circ}$ for the two independent complexes, respectively. Pairs of trans-ethylisonicotinate ligands are non-coplanar. The angle between their planes is 56.4 and $72.9^{\circ}$ in one complex and 61.4 and $70.8^{\circ}$ in the other. Although there is nothing remarkable about these data, they contain the suggestion that significant molecular flexibility is inherent in these complexes. This is also reflected by the positional disorder of one ethyl residue in the ester groups $(\mathrm{O} 10 A / B, \mathrm{C} 43 A / B$ and $\mathrm{C} 44 A / B)$ in the ligands of $\mathrm{Ni} 2$, with the refined ratio of residue $A$ to residue $B$ being 0.848 (3):0.152 (3).

\subsection{Crystal structure of $\left[\mathrm{Ni}\right.$ (methylisonicotinate) $\left.{ }_{4}(\mathrm{NCS})_{2}\right]$ (II)}

Compound (II) crystallizes in space group $P 2_{1} / n$. The asymmetric unit contains three independent molecular units, of which one is positioned on an inversion centre ( $\mathrm{Ni3}$ at $\left.\frac{1}{2}, 0, \frac{1}{2}\right)$, giving $Z^{\prime}=2.5$. The complexes do not differ greatly, except in that in the centrosymmetric complex the ligand rings in trans positions are coplanar, while they rotated against each other by between 64 and $81^{\circ}$ in the non-centrosymmetric complexes. The organic ligands do not show any indications for the disorder observed in the crystal structure of (I). Only one SCN ligand in the coordination sphere of $\mathrm{Ni} 2$ shows some orientational disorder. The coordinating $\mathrm{N}$ atom shows no disorder, but the remainder of the ligand points in two different directions leading to split positions for the respective $\mathrm{C}$ and $\mathrm{S}$ atoms. The refined site occupancies of the disordered parts of the ligand (S4A/B and C32A/B) are 0.734 (3):0.266 (3).

The principal structural features of (II) and the atomnumbering scheme are illustrated in Fig. 2. Selected interatomic distances and bond angles involving $\mathrm{Ni}^{\mathrm{II}}$ are listed in Table 3. In each complex, the distorted octahedral $\mathrm{Ni}^{\mathrm{II}}$ is coordinated by four methylisonicotinate ligands, with the coordinating $\mathrm{N}$ atoms forming a square-planar arrangement. The $\mathrm{Ni}-\mathrm{N}$ distances range from $2.100(3)(\mathrm{Ni2}-\mathrm{N} 12)$ to 2.207 (3) $\AA(\mathrm{Ni3}-\mathrm{N} 14)$ and the $\mathrm{N}-\mathrm{Ni}-\mathrm{N}$ bond angles from 86.23 (10) to $93.77(10)^{\circ}$ (cis) and 173.06 (10) to $180^{\circ}$ (trans). For the $N$-bonded trans-thiocyanate ligands, the $\mathrm{Ni}-\mathrm{N}$ distances are in the range 2.036 (3) to 2.060 (3) $\AA$, while the $\mathrm{N}-\mathrm{Ni}-\mathrm{N}$ bond angles have values of 177.90 (11) to $180^{\circ}$. Pairs of trans-methylisonicotinate ligands in the non-centrosymmetric complexes are non-coplanar. The angle between their planes is 63.8 and $71.6^{\circ}$ in one complex, 79.4 and $80.9^{\circ}$ in the second, and zero in the centrosymmetric case. The fact that the two trans-pyridine rings are not coplanar in two of the crystallographically independent complexes but coplanar in the third is indicative of considerable molecular flexibility, which has already been noted for (I) and is relevant when we consider the molecular packing. However, this flexibility appears to be principally associated with the square plane of organic ligands. Table 3 shows that angles at $\mathrm{Ni}^{\mathrm{II}}$ involving a thiocyanate ligand and an 'organic' $\mathrm{N}$ are usually close to $90^{\circ}$, whereas those subtended by two 'organic' $\mathrm{N}$ atoms are significantly more variable. The isothiocyanate ligands in (II) act as terminal $N$-ligands rather than bridging ligands, so there is no extended bonding, which would otherwise be a dominating influence on the molecular packing.

\subsection{Crystal structure of $\left[\mathrm{Ni}(4-\text {-benzoylpyridine })_{4}(\mathrm{NCS})_{2}\right]$ (III)}

Complex (III) crystallizes in the space group $P 2_{1} / c$. It is a centrosymmetric, mononuclear, distorted octahedral complex in which $\mathrm{Ni}^{\mathrm{II}}$ is coordinated to four 4-benzoylpyridine ligands in a square-planar arrangement and to two thiocyanate ligands in a trans arrangement. There are no indications of any disorder in the crystal structure. The principal structural features of (III) and the atomic numbering scheme are illustrated in Fig. 3. Selected bond distances and angles are listed in Table 4.

\subsection{IR spectra}

The vibrational characteristics of an SCN group coordinated to a metal ion are well known (Mitchell \& Williams, 1960; Bala et al., 2006). The $M-\mathrm{NCS}$ and $M-\mathrm{SCN}$ modes of coordination may sometimes be distinguished (Norbury, 1975) in that the $v(\mathrm{CN})$ frequencies are generally lower for the former, where they are usually found at $c a 2100 \mathrm{~cm}^{-1}$ (Clark \& Goodwin, 1970; Ferraro, 1971). The $v(\mathrm{C}-\mathrm{S})$ values provide a more useful distinction. The relevant frequencies are 780 $860 \mathrm{~cm}^{-1}$ for $M-\mathrm{NCS}$ and $690-720 \mathrm{~cm}^{-1}$ for $M-\mathrm{SCN}$. The NCS bending frequency is also different for the two modes: $450-490 \mathrm{~cm}^{-1}$ for $M-\mathrm{NCS}$ and $400-440 \mathrm{~cm}^{-1}$ for $M-\mathrm{SCN}$ (Keller et al., 1968). In the IR spectra of (I)-(III), a sharp absorption band in the $2070-2080 \mathrm{~cm}^{-1}$ region is consistent with the $N$-coordinated $\mathrm{SCN}$ group observed in the crystal structures. There is no spectral evidence for the presence of the crystallographically distinct species in (I) or (II), or of any vibrational coupling between different molecules (factor group splitting). The $v(\mathrm{C}-\mathrm{S})$ modes in the spectra are overlapped by pyridine stretching and deformation bands, making the assignment of the $700-800 \mathrm{~cm}^{-1}$ region quite uncertain. The same is true for the $\sim 400 \mathrm{~cm}^{-1}$ region. It could be possible to make progress by a study of isotopically enriched molecules, but the cost and efforts involved are probably not justified.

\subsection{Thermal analysis}

Thermogravimetric analysis (TGA) of (I)-(III) was performed on crystalline samples over the temperature range 298-1073 K under a flowing $\mathrm{N}_{2}$ atmosphere (see the supporting information). Under ambient conditions, the crystals possess good stability and do not show any hygroscopicity. TGA shows that (I) is thermally stable up to $403 \mathrm{~K}$. The compound decomposes in three consecutive steps over the temperature range $403-463 \mathrm{~K}$, followed by a slow decomposition up to $1023 \mathrm{~K}$, leaving a residue, presumably largely of $\mathrm{Ni}$ metal (experimental weight $8.36 \%$, calc. for $\mathrm{Ni}$ $7.53 \%$ ). Compound (II) is stable up to $383 \mathrm{~K}$, above which decomposition occurs. Between 373 and $823 \mathrm{~K}$ five stages could be distinguished, but they could not be unambiguously described, and it seems that several different processes take place concurrently. The solid residue $(11.67 \%)$ at the end of 


\section{crystal engineering}

the analysis must contain $\mathrm{Ni}$, but it was not characterized. In contrast, compound (III) is stable up to $463 \mathrm{~K}$. Between 463 and $663 \mathrm{~K}$, there are three decomposition stages. The residual solid $(6.48 \%)$ is apparently metallic $\mathrm{Ni}$ (calc. 6.49\%). An explanation for the enhanced thermal stability of (III) compared with the other two compounds is offered later.

\subsection{Molecular packing}

In the design of coordination complexes for potential applications, it is common for polar units to be incorporated either as a ligand or as a substituent within a ligand. Their presence facilitates, for example, charge transfer between metal centres and so the migration of excitons. However, such migration also depends on molecular orientations. A relevant question, therefore, concerns the way in which polar units influence molecular orientations/molecular packing (see Fig. 4 for packing diagrams). The presence of polar groups in a molecule may enhance exciton migration but their effect on packing may negate it. We believe that complexes (I)-(III) contain molecular components that significantly influence the packing. Whilst the organics ligand of (I) and (II) contain a single ring system, that of (III) contains two. In addition, the 'organic' ligand component of (III) is the most bulky, containing 23 atoms compared with 16 for (I) and 20 for (II).

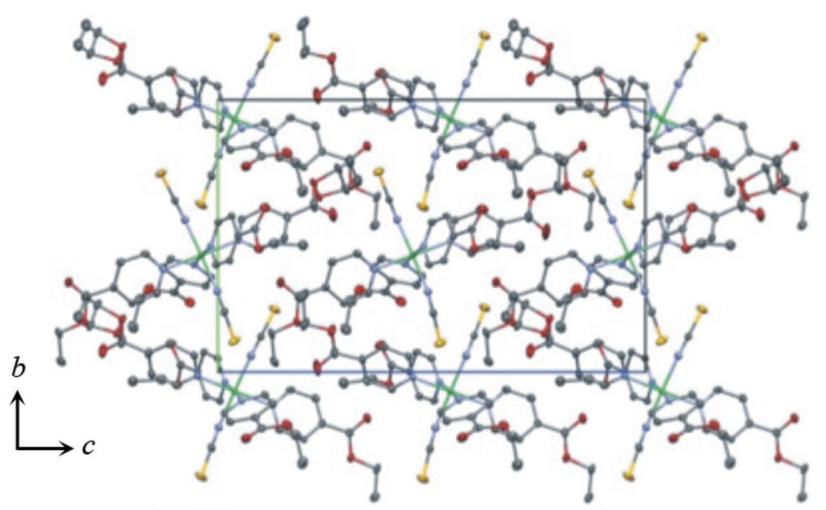

(a)

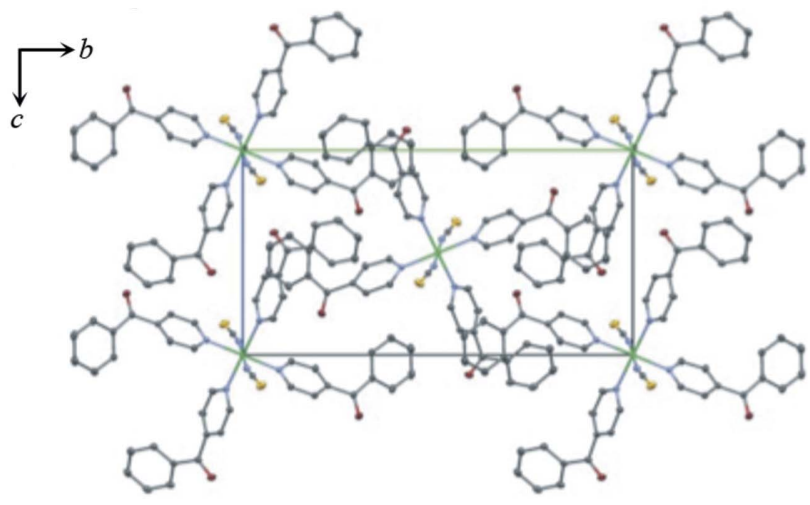

(c)
In that these ligands all radiate from a common $\mathrm{Ni}^{\mathrm{II}}$ centre, it might be anticipated that the smaller the ligand, the denser the packing, since the shape is more regular (Motherwell, 2010). On the other hand, (I) and (II) have two polar O substituents at the periphery of a pyridine-based ligand, while for (III) there is a single polar $\mathrm{O}$ substituent embedded in the centre of a similar ligand. In that they are the more exposed, and so available for mutual repulsion, it could be that the polar substituents in (I) and (II) will cause these species to have the less dense packing. If these arguments have some validity, the present structures seem to enable a simple distinction: which has the greater effect on packing, a bulky, bumpy, shape or exposed polarity? If the conclusion has some generality, it would indicate a direction for ligand design.

A simple measure to assess packing efficiency is the crystal density. For (I)-(III), the difference is quite dramatic (Table 1). Notwithstanding their evident molecular flexibility - (I) and (II) having different conformers in the unit cell, while (III) is apparently less flexible - (I) and (II) both have density $1.408 \mathrm{~g} \mathrm{~cm}^{-3}$. In comparison, (III) has density $1.454 \mathrm{~g} \mathrm{~cm}^{-3}$. This is also despite the fact that the 'heavy atom' $\left(\mathrm{NiS}_{2}\right)$ contribution to the molecular weight is a significantly smaller fraction for (III), as reflected in the calculated values for the elemental analysis in $\$ 2.2$. It may be that the difference in packing is also evident in the results of the thermal analysis,

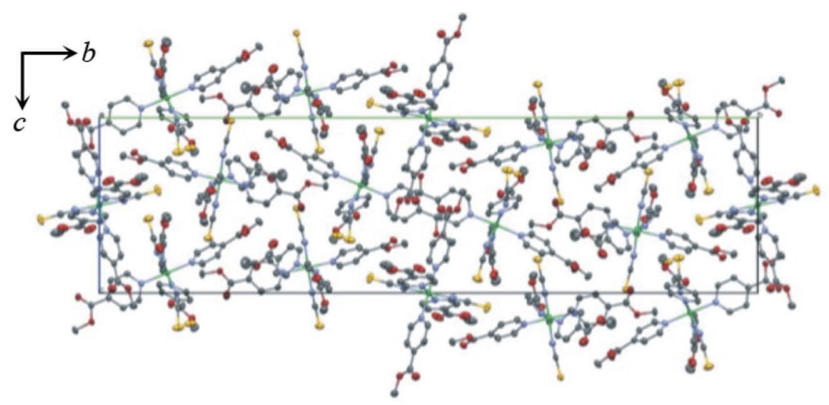

(b)

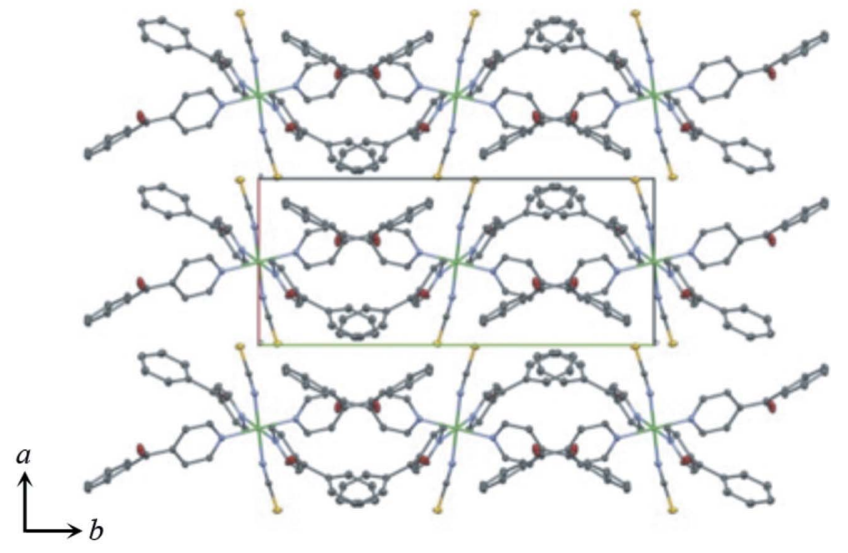

(d)

Figure 4

Projections of the crystal structures: (a) (I) viewed down [100]; (b) (II) viewed down [100]; (c) (III) viewed down [100]; (d) (III) viewed down [001]. H atoms are omitted. 
since (III) has a significantly greater thermal stability than either (I) or (II).

It seems highly unlikely that the difference in density is a consequence of density differences of the pure organic solids. There are no crystal structures of the three ligands (the isonicotinates are liquids at room temperature), but the crystal structures for the corresponding benzene derivatives, methylbenzoate (Yakovenko et al., 2011) and benzophenone (Kutzke et al., 2000), have been determined. For these, the ester has a slightly higher density $\left(1.298 \mathrm{~g} \mathrm{~cm}^{-3}\right)$ than the ketone $\left(1.269 \mathrm{~g} \mathrm{~cm}^{-3}\right)$.

To determine if these density values are high or low, the Cambridge Structural Database (CSD; Allen, 2002) was searched (three-dimensional coordinates determined, not disordered, not polymeric, no powder structures, $R$ values less than or equal to 0.10 , error free) for compounds with a total formula similar to (I)-(III), thus within the range $\mathrm{C}_{30-50} \mathrm{H}_{20-40} \mathrm{NiN}_{1-4} \mathrm{O}_{2-8} \mathrm{~S}_{1-4}$. For 30 such structures found, the density displayed a broad distribution between the extreme values $1.285 \mathrm{~g} \mathrm{~cm}^{-3}$ (CERYUT; Cabaleiro et al., 1999) and $1.620 \mathrm{~g} \mathrm{~cm}^{-3}$ (GESVEG; Gándara et al., 2006), with a mean value of $1.448 \mathrm{~g} \mathrm{~cm}^{-3}$. Thus, while our values are not extreme, the difference between them is still significant. We also note that the structures CERYUT and GESVEG have similar formulae, $\mathrm{C}_{36} \mathrm{H}_{30} \mathrm{~N}_{6} \mathrm{NiO}_{4} \mathrm{~S}_{2}$ and $\mathrm{C}_{34} \mathrm{H}_{24} \mathrm{~N}_{4} \mathrm{NiO}_{7} \mathrm{~S}_{2}$, indicating that the number of third and fourth period elements in the formula is not decisive.

We can further analyse (I)-(III) using the 'Kitaigorodski packing coefficient' as implemented in PLATON (Spek, 2009), giving an indication of percent space filled. The following values are obtained: (I) 68.3; (II) 66.3; (III) 71.9\%. Of these, (II) stands out with a value lower than expected for a centrosymmetric structure (being usually more efficiently packed for symmetry reasons), and the PLATON analysis also

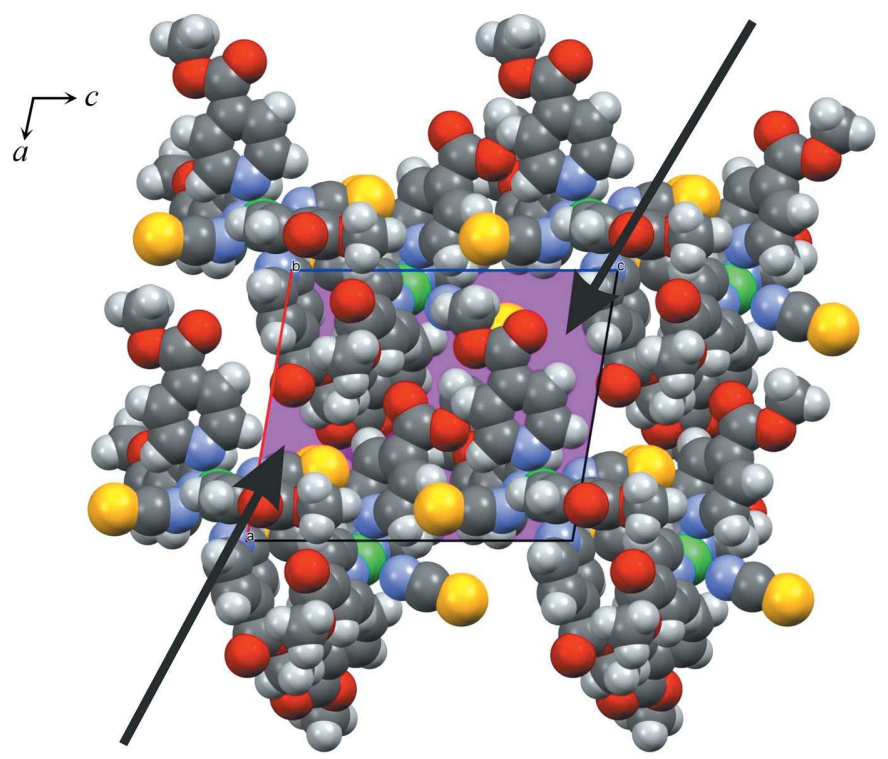

Figure 5

View of (II) along the $b$ axis, showing voids (approximately at $0.25,0.25$, 0.6 and $0.75,0.25,0.1$, at the glide plane at $y=1 / 4$ ) marked with arrows. indicates the presence of voids in the structure. Using the default settings in Mercury (probe radius $1.2 \AA$; Macrae et al., 2008), (I) and (III) do not show any voids, but (II) shows clear voids amounting to $c a 175 \AA^{3}$ per unit cell $(2.1 \%$ of the cell volume; Fig. 5).

Thus, we have three similar compounds of which one unambiguously has a higher density and packing coefficient, indicating a more efficient packing. Also, the difference in the packing coefficient between the centrosymmetric structures (II) and (III) indicate that the molecules in (II) have problems packing efficiently, and voids are also apparent in the structure of (II). In an effort to understand these features, we consider two methods, one of which interrogates the crystal structure in depth (Hirshfeld surfaces) and the other which studies the isolated molecules (DFT calculations).

\subsection{Hirshfeld surfaces}

Although experimental electron densities can be determined, they offer incomplete insight into molecular packing because of the absence of knowledge of the surface at which one molecule 'ends' and another 'begins'. Hirshfeld surfaces overcome this problem by replacing each atom with its spherically averaged theoretical electron density counterpart (Spackman \& McKinnon, 2002; McKinnon et al., 2004, 2007; Spackman et al., 2008; Spackman \& Jayatilaka, 2009). The origin of each contribution to the total electron density is thus known. The surface generated by those points at which the calculated electron density from the chosen molecule equals that from the surrounding molecules defines the Hirshfeld surface. Inside this surface, the electron density is dominated by the electron density belonging to the chosen molecule. Bonding interactions are ignored but this should not be important in external regions of space. Hirshfeld surfaces for compounds (I)-(III) are shown in Fig. 6, with close intermolecular atom-atom contacts indicated by red areas. For (I) and (II), which exhibit disorder, only the main disorder component was used. Each view is almost along the pseudofourfold axis of each molecule, in order to emphasize the surfaces of the organic ligands, which are most likely to reveal the source of the packing differences. Whilst some differences in the surfaces are evident, they offer no obvious explanation for packing anomalies. This is not an unusual situation and techniques have been developed which enable deeper enquiry.

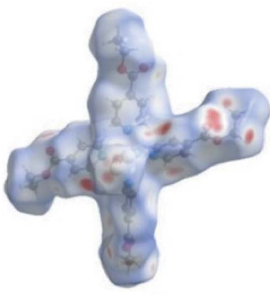

(I)

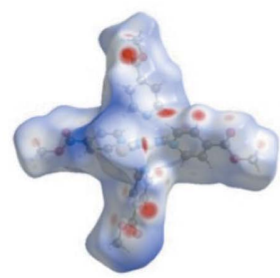

(II)

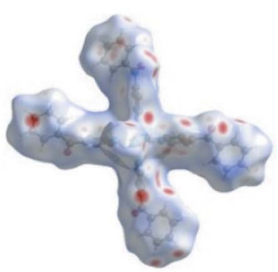

(III)
Figure 6

Hirshfeld surfaces for compounds (I)-(III) with close intermolecular contacts indicated by red areas. 
The easiest way to interrogate Hirshfeld surfaces is by the use of fingerprint plots. The surface is covered by a fine-mesh net and, at each point of the mesh, the nearest atom of the chosen molecule (internal to the surface) and the nearest of the surrounding (external) atoms determined. The distance to the nearest internal atom, denoted $d_{i}$, along with that to the nearest external atom, denoted $d_{\mathrm{e}}$, are recorded. A fingerprint diagram is a plot of $d_{\mathrm{i}}$ against $d_{\mathrm{e}}$, containing all points determined in this way. Fingerprint plots for each unique complex in (I)-(III) are given in the supporting information. In each case the aggregated point density is shown in grey, with a selected component being given in blue (then green, yellow and red as the density increases). The percentage of points arising from the blue/red contribution is indicated. They total more than $100 \%$ because of double counting (so, C $\cdots \mathrm{H}$ contributes to both $\mathrm{H}$ and $\mathrm{C}$, we use the option: include reciprocal contacts').

An observed crystal structure has to be the result of a precise balance of attractive and repulsive forces. Put another way, when an about-to-be-incorporated molecule approaches a crystal surface, any repulsive forces would cause it to orientate so as minimize their contribution. This structuredetermining factor finds no overt expression in the Hirshfeld surface. For us, this is a problem because a possible reason for the higher density of (III) lies in additional polar repulsive interactions between $\mathrm{O}$ atoms in (I) and (II). Nonetheless, we believe that it is possible to use the Hirshfeld approach to assess this suggestion, by considering the fingerprint plots. The most polar atom is $\mathrm{O}$ and so we consider 'contacts with $\mathrm{O}$ '. For (III) these represent $15.7 \%$ of the points in the fingerprint

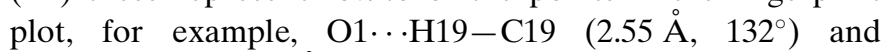
$\mathrm{O} 1 \cdots \mathrm{H} 2-\mathrm{C} 2\left(2.58 \AA, 129^{\circ}\right)$. For (I) they represent 21.6 and $20.9 \%$ for the two complexes in the asymmetric unit. For (II) they represent 27.9, 27.7 and $24.9 \%$ for the three independent complexes. The percentage of $\mathrm{O} \cdots \mathrm{O}$ contacts is small in all structures: $0.4 \%$ in (I), $1.7 \%$ in (II) and $0.0 \%$ in (III). Although they cannot be definitive, the Hirshfeld surfaces are consistent with the packing differences originating in $\mathrm{O} \cdots \mathrm{O}$ repulsions. In that they are also electronegative, one might also query the role of the $\mathrm{S}$ atoms. In (III) $\mathrm{S}$ is involved in $14.2 \%$ of the contacts, whilst in (I) the figure is 16.4 and $16.9 \%$ for the two independent complexes, and for (II) it is 21.0, 18.3 and $20.0 \%$ for the three independent complexes. In (II) this
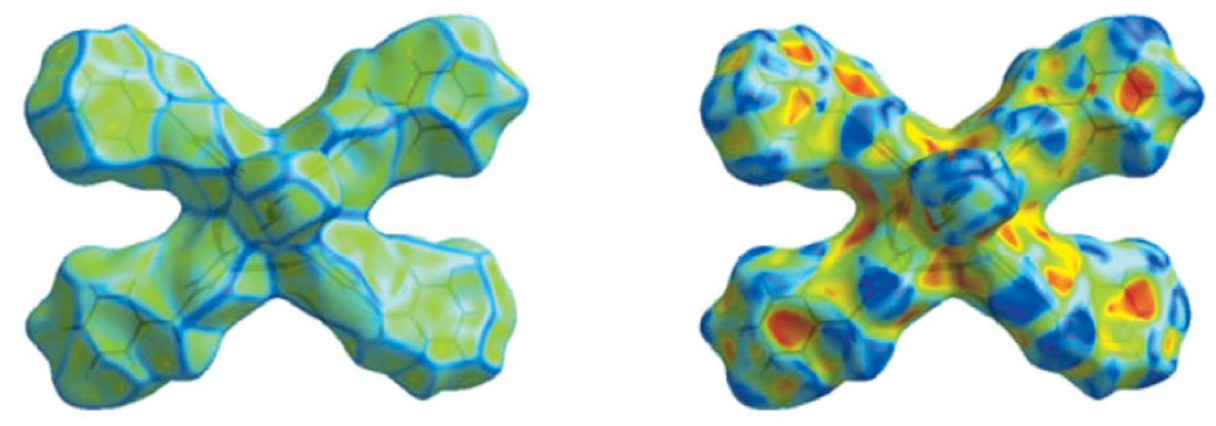

Figure 7

(a) Curvedness and (b) shape index mapped on the Hirshfeld surface of (III). can be exemplified by $\mathrm{S} \cdot \mathrm{H}-\mathrm{C}$ interactions such as $\mathrm{S} 1 \cdots \mathrm{H} 18-\mathrm{C} 18\left(3.11 \AA, 155^{\circ}\right), \mathrm{S} 2 \cdots \mathrm{H} 21 C-\mathrm{C} 21 \quad(3.00 \AA$, $\left.130^{\circ}\right)$ and $\mathrm{S} 2 \cdots \mathrm{H} 46 \mathrm{C}-\mathrm{C} 46\left(2.93 \AA, 136^{\circ}\right)$, and in (III) by $\mathrm{S} 1 \cdots \mathrm{H} 23-\mathrm{C} 23\left(3.03 \AA \mathrm{A}^{\circ}, 149^{\circ}\right)$. The $\mathrm{S} \cdots \mathrm{S}$ contacts are $0.0 \%$ for (I), $0.0 \%$ for (II) and $0.1 \%$ for (III). The S. . O contacts are similarly small: $1.5 \%$ for (I), $1.3 \%$ for (II) and $0.0 \%$ for (III). Whilst they also cannot be held to be conclusive, these data are also in accordance with our earlier suggestion: there is minimal contact between electronegative atoms. Contacts involving $\mathrm{O}$ atoms probably dominate but a possible contribution from $\mathrm{S}$ atoms in (III) cannot be excluded.

Another route is to investigate $\mathrm{H} \cdots \mathrm{H}$ repulsion and $\mathrm{H} \cdots \mathrm{O}$ attraction, the hypothesis being that fewer $\mathrm{H} \cdots \mathrm{H}$ contacts and more $\mathrm{H}$. . O contacts should be a sign of better packing. We find (average values) for (I): $\mathrm{H} \cdots \mathrm{H} 43 \%, \mathrm{H} \cdots \mathrm{O} 18 \%$; (II)

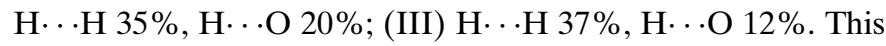
would suggest (II) as having the most efficient packing, which seems not to be the case.

Do the Hirshfeld data offer any assessment of alternative suggestions to explain the packing differences? In (III) C. . C interactions are involved in $5.0 \%$ of the fingerprint points. In contrast, in (I) they are involved in only 0.6 and $0.4 \%$; in (II) the corresponding values are $1.7,2.9$ and $1.8 \%$. The number of $\mathrm{C}$ atoms in each complex is 30,34 and 50, so the above data may, at least in part, be a consequence of the compositions of the three materials. Nonetheless, in principle at least, $\pi-\pi$ interactions are possible. The suggestion that $\pi-\pi$ stacking interactions are of relevance to the packing in these materials (Đaković et al., 2008) can be tested by plotting the curvedness and shape index of the Hirshfeld surfaces. The curvedness and shape index at a point on the surface are derived from the gradients of two vectors perpendicular to the normal at that point. For strong $\pi-\pi$ stacking the curvedness should show flat regions, but less intuitive are the triangular patterns with reversed signs on the shape index maps, shown by McKinnon et al. to be an indicative feature of $\pi-\pi$ stacking (McKinnon $e t$ al., 2004). Fig. 7 shows these surfaces plotted for (III) and while some flat curvature is found on top of the benzene rings, the shape index pattern is not that associated with strong $\pi-\pi$ stacking. That is, such stacking does not offer an explanation for the tighter packing observed in (III). On the contrary, the same procedure for the extreme density structures (CSD refcodes CERYUT and GESVEG) indicates that the low density compound has only $0.8 \%$ C. .C contribution to the Hirshfeld surface, while the high density compound shows a significantly higher value than for (III), 8.2\%, and the characteristic shape-index pattern indicating efficient $\pi-\pi$ stacking.

The only other interaction unique to (III) that we have been able to identify is $\mathrm{H} \cdots \pi$ (aromatic), but this is scarcely sufficient to account for the observed density difference. Hirshfeld surfaces, by a 
process of elimination, therefore point to repulsive interactions between electronegative atoms as responsible for the greater density of (III); of the compounds studied it has the minimum.

Spackman has also suggested that electrostatic potentials mapped on Hirshfeld surfaces may provide direct insight into intermolecular interactions, and especially the concept of electrostatic complementarity can be explored (Spackman et al., 2008). This points to an investigation into the charge distributions in (I)-(III). For this, we turn to DFT calculations, although a combined DFT-Hirshfeld analysis has not been performed.

\subsection{DFT calculations}

In order to study the effect of the substituent at the pyridine on the electronic and spectroscopic properties of compounds (I)-(III), we performed DFT/B3LYP calculations using the 6$31 \mathrm{G}(\mathrm{d})$ basis set. The starting input geometries were taken from the crystal structures, but subsequently allowed to optimize. The calculations were performed using GAUSSIAN03 software (Frisch et al., 2004; Dennington et al., 2003). In the case of (III), calculations performed with and without inversion symmetry constraints made very little difference to the
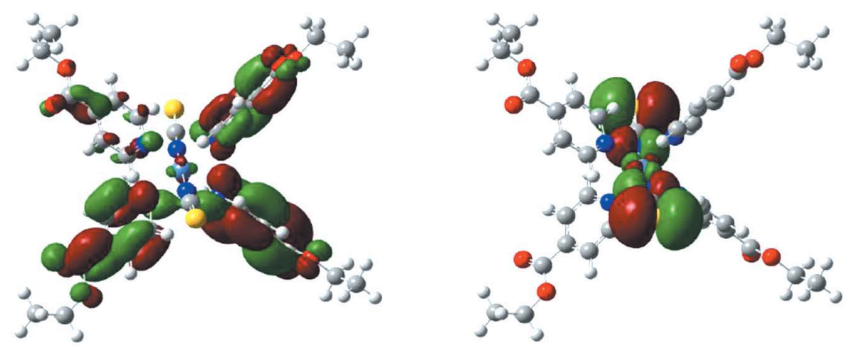

(I)
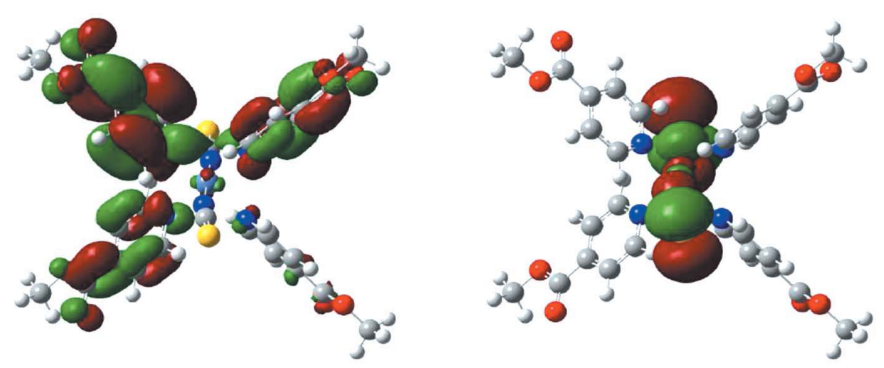

(II)
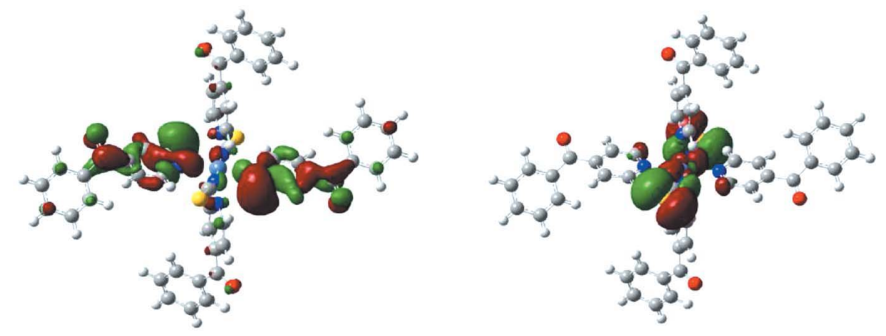

(III)

Figure 8

Lowest-unoccupied (LUMO; left) and highest occupied (HOMO; right) molecular orbitals calculated for the isolated complexes (I)-(III). output (energy difference less than or equal to $1 \mathrm{~kJ} \mathrm{~mol}^{-1}$ ), and the discussion is based on the calculations with $C_{i}$ symmetry constraints.

Since the calculations are performed on single isolated molecules in the gas phase, the results should act as reference points which show the consequences of molecular packing. Selected calculated bond distances and bond angles for (I)(III) are included in Tables 2-4. In general, there is good agreement between the calculated and experimental values, giving confidence that the DFT data can provide real insights. Of the three complexes, only (III) is predicted to have any non-trivial symmetry $\left(C_{i}\right)$. The other complexes show small twists of the organic ligands which serve to reduce the symmetry, although there is no evident pattern to, or origin of, these twists. We take this as support for the conclusion reached from the X-ray structures, that these are flexible molecules. The general electronic structures obtained are similar. For each, the HOMO is an orbital located on the NCS ligands (Fig. 8, right). The LUMO is localized on the organic ligands, with that for (I) and (II) mostly involving three of the ligands, while that for (III) involves two (Fig. 8, left). In that all the molecules have an idealized fourfold symmetry, it is not surprising to find the LUMO asymmetry approximately compensated for in a proximate unoccupied molecular orbital (MO).

We were interested to use the DFT calculations as an assessment of the molecular polarity explanation for the differences in molecular packing. The difference in molecular symmetry ensures that only (I) (2.13 D) and (II) (3.38 D) are polar, both having the dipole in the plane of the organic ligands. However, this finding may not be too significant in view of the evident molecular flexibility. Probably more important are the (Mulliken) atomic charges. These are surprising. One might anticipate that, having a larger number of electronegative atoms, the intrinsic molecular charge in (I) and (II) would be distributed and so would have lower values than for (III). This is not found: in (III) the calculated average charge on $=\mathrm{O}$ is -0.446 , whereas for (I) and (II) it is -0.477 and -0.473 , respectively. In (I) and (II) the average charge on $-\mathrm{O}$ is -0.472 and -0.461 , respectively. A similar pattern holds for S: for (III) the calculated charge is -0.304 , but for (I) and (II) the average is -0.313 and -0.315 , respectively. Although all of the complexes have essentially the same average calculated charge on $\mathrm{N}($ py) $(-0.496)$, the $\mathrm{N}(\mathrm{SCN})$ has a lower charge in (III) $(-0.513)$ than the average in (I) and (II) $(-0.528$ and -0.527 , respectively). All indicators point to the same conclusion: (III) exhibits lower intrinsic polarity than (I) and (II). Thus, the DFT calculations support the conclusion that the crystal packing differences originate in different molecular polarities. A pictorial representation of this conclusion is to be found in the molecular electrostatic potentials (MEPs) calculated for the three molecules (Fig. 9; Cieplak, 1991; Murray \& Sen, 1996; Scrocco \& Tomasi, 1978). The red regions of the MEPs indicate negative sites while the turquoise regions correspond to positive sites. It can be seen that the most negatives sites are associated with the $\mathrm{O}$ and $\mathrm{S}$ atoms. 
Table 5

Hirshfeld analysis of the intermolecular contacts involving the $\mathrm{O}$ atoms of (I)-(III)

\begin{tabular}{llll}
\hline & Molecule & $\mathrm{O} \cdots \mathrm{O}(\%$ of surface $)$ & $\mathrm{S} \cdots \mathrm{O}(\%$ of surface $)$ \\
\hline (I) & $A$ & 0.5 & 1.4 \\
& $B$ & 0.4 & 1.6 \\
(II) & $A$ & 1.3 & 1.9 \\
& $B$ & 2.3 & 1.4 \\
& $C$ & 1.5 & 0.7 \\
(III) & $A$ & 0.0 & 0.1
\end{tabular}

\section{Discussion}

All of the available evidence points to a single conclusion: that the greater crystal density of (III) originates in a crystal packing resulting from smaller intermolecular electrostatic repulsions. An additional contributor may be that the polar $\mathrm{O}$ atoms in (I) and (II) are more at the periphery of the molecule than in (III). The question that immediately arises is whether these conclusions find support in the observed crystal structures. Figs. 4(a)-(c) shows projections of (I)-(III) down the shortest crystal axes, and the comparison shows (III) to have $\mathrm{O}$ atoms clearly separated, unlike (I) and (II). However, this comparison is marred by the fact that (III) has the smallest unit cell. Perhaps a more accurate comparison is provided by Figs. 4(a), $(b)$ and $(d)$, for which the axes of projection are of comparable length. Again, (III) emerges as showing the most separated $\mathrm{O}$ atoms.

A more quantitative analysis is provided by the Hirshfeld surfaces, from which the percentage of surface associated with each interaction type can be calculated. The results of such an analysis are given in Table 5 and are quite unambiguous. In compound (III) the intermolecular interactions involving the $\mathrm{O}$ atoms are an order of magnitude smaller than for any of the molecules of (I) and (II). Full details of this analysis are given in the supporting information.

The two extreme examples of low and high density identified in the CSD, CERYUT and GESVEG, predictably deviate from this pattern. Thus, while in GESVEG the $\mathrm{O} \cdots \mathrm{O}$ and $\mathrm{S}$. . O interactions are absent, just as for (III) the much higher density probably comes from efficient $\pi-\pi$ stacking, while in
CERYUT the surface is dominated by interactions involving $\mathrm{H}(99.1 \%)$. It should be noted that low density can also be achieved by relatively strong directional interactions such as weak hydrogen bonds, provided the geometry allows the formation of networks.

We believe that this analysis serves to establish the origin of the different packing densities of compounds (I)-(III). This insight indicates the need to consider the consequences for packing of molecular choices made with the aim of enhancing specific properties of solids. The question at once arises of whether other molecular interactions could play a similar role, with the expectation that the answer would be in the affirmative. Further insights into other relevant interactions could well be gained by systematic study of crystallographic databases such as the CSD. Variations in crystal densities of rather similar compounds may point to pertinent examples.

Although it is evident that molecular packing as a topic in its own right is no less important than a study of intermolecular interactions in determining the properties of a solid, it is a topic that has attracted far less attention (Desiraju et al., 2011). In the protein field, in particular, it is recognized that chemical variations can have a profound effect on intermolecular interactions and thus on molecular packing. So, there has been recognition of the importance of hydrogen bonding on the one hand and repulsive interactions between halogens on the other (Metrangolo et al., 2005; Desiraju, 2011). In large molecules, numerous small interactions can accumulate to give a clearly evident outcome. For small molecules, the situation is much more difficult and there have not been comparable extensive studies. In the present work we have drawn attention to a measurement which is always made but not always discussed, namely that of crystal density (in crystal structure predictions it is recognized as an important parameter). A study of crystal densities of related small molecules serves to draw attention to cases of very different packing, which can then be further explored. The present work has provided an example of this, although it is an unexpected aspect which emerged whilst the chemical work was in progress. More specifically targeted work would be expected to lead to significant progress. The recognition of the most important interactions controlling the molecular packing of small molecules would surely have an impact on the rational design of economically important polymeric inorganic materials. It is noteworthy that significant progress has been made in the organic field (Day et al., 2009); the next major step must surely be in the inorganic field.

\section{Conclusion}

Three new monomeric distorted octahedral trans-[Ni $\left.L_{4}(\mathrm{NCS})_{2}\right][L=$ ethylisonicotinate (I), methylisonicotinate (II), 4-benzoylpyridine (III)] complexes were prepared, and single-

Molecular electrostatic potentials (MEP) mapped on the DFT/B3LYP electron density surface for (I)(III). 
crystal X-ray structures showed that the three complexes have distorted octahedral geometries with two terminal $N$-bonded thiocyanate ligands. This similarity was in contrast to their crystal densities, which suggested that terminal polar groups on organic substituents lead to a lower density than when the groups are less polar and less exposed. Although this aspect was not originally planned as part of the work, its recognition led to this study. It could be important in that it is a largely neglected aspect of coordination chemistry. A more complete recognition of interactions of potential importance in molecular packing would be of value in fields as diverse as the design of inorganic polymers and calculations on molecular crystals.

LÖ thanks the Swedish Research Council and LÖ and MAMAY acknowledge support from the International Development Agency (SIDA) through the Swedish Research Links Program.

\section{References}

Allen, F. H. (2002). Acta Cryst. B58, 380-388.

Bala, R., Sharma, R. P., Sharma, R. \& Kariuki, B. (2006). Inorg. Chem. Commun, 9, 852-855.

Bruker (2008). APEX2, SADABS, SAINT and SHELXTL. Bruker AXS, Madison, Wisconsin, USA.

Burmeister, J. L. (1975). The Chemistry and Biochemistry of Thiocyanic Acid and its Derivatives, edited by A. A. Newman, pp. 68-130. London: Academic Press.

Burmeister, J. L. (1990). Coord. Chem. Rev. 105, 77-133.

Cabaleiro, S., Castro, J., Vázquez-López, E., Garcia-Vázquez, J. A., Romero, J. \& Sousa, A. (1999). Polyhedron, 18, 1669-1674.

Cieplak, P. (1991). J. Comput. Chem. 12, 1232-1236.

Clark, R. J. H. \& Goodwin, A. D. J. (1970). Spectrochim. Acta A, 26, 322-330.

Đaković, M., Popović, Z. \& Smrečki-Lolić, N. (2008). J. Mol. Struct. 888, 394-400.

Đaković, M., Vila-Viçosa, D., Calhorda, M. J. \& Popović, Z. (2011). CrystEngComm, 13, 5863-5871.

Day, G. M. et al. (2009). Acta Cryst. B65, 107-125.

Dennington, R. II, Keith, T., Millam, J., Eppinnett, K., Hovell, W. L. \& Gilliland, R. (2003). GAUSSVIEW, Version 3.03. Semichem Inc., Shawnee Mission, Kansas, USA.

Desiraju, G. R. (2011). Cryst. Growth Des. 11, 896-898.

Desiraju, G. R., Vittal, J. J. \& Ramanan, A. (2011). Crystal Engineering. A Textbook. Singapore: World Scientific.

Fafarman, A. T., Koh, W. K., Diroll, B. T., Kim, D. K., Ko, D. K., Oh, S. J., Ye, X., Doan-Nguyen, V., Crump, M. R., Reifsnyder, D. C., Murray, C. B. \& Kagan, C. R. (2011). J. Am. Chem. Soc. 133, 1575315761.
Ferraro, J. R. (1971). Low-Frequency Vibrations of Inorganic and Coordination Compounds. New York: Plenum Press.

Flack, H. D. (1983). Acta Cryst. A39, 876-881.

Frisch, M. J. et al. (2004). GAUSSIAN03. Gaussian Inc., Pittsburgh, Pennsylvania, USA.

Gándara, F., Fortes-Revilla, C., Snejko, N., Gutiérrez-Puebla, E., Iglesias, M. \& Monge, M. A. (2006). Inorg. Chem. 45, 9680-9687.

Gavezzotti, A. (2008). CrystEngComm, 10, 389-398.

Goher, M. A., Mautner, F. A., Abu-Youssef, M. A., Hafez, A. K., Badr, A. M. \& Gspan, C. (2003). Polyhedron, 22, 3137-3143.

Keller, R. N., Johnson, N. B. \& Westmoreland, L. L. (1968). J. Am. Chem. Soc. 90, 2729-2730.

Kutzke, H., Klapper, H., Hammond, R. B. \& Roberts, K. J. (2000). Acta Cryst. B56, 486-496.

Macrae, C. F., Bruno, I. J., Chisholm, J. A., Edgington, P. R., McCabe, P., Pidcock, E., Rodriguez-Monge, L., Taylor, R., van de Streek, J. \& Wood, P. A. (2008). J. Appl. Cryst. 41, 466-470.

McKinnon, J. J., Jayatilaka, D. \& Spackman, M. A. (2007). Chem. Commun. pp. 3814-3816.

McKinnon, J. J., Spackman, M. A. \& Mitchell, A. S. (2004). Acta Cryst. B60, 627-668.

Metrangolo, P., Neukirch, H., Pilati, T. \& Resnati, G. (2005). Acc. Chem. Res. 38, 386-395.

Mitchell, P. C. H. \& Williams, R. J. P. (1960). J. Chem. Soc. p. 1912.

Motherwell, W. D. S. (2010). CrystEngComm, 12, 3554-3570.

Murray, J. S. \& Sen, K. (1996). Molecular Electrostatic Potentials, Concepts and Applications. Amsterdam: Elsevier.

Norbury, A. H. (1975). Advances in Inorganic and Radiochemistry, Vol. 17, edited by H. J. Emeléus \& A. G. Sharpe, pp. 231-386. New York: Academic Press.

Quan, Y., Yin, P., Han, N., Yang, A., Gao, H., Cui, J., Shi, W. \& Cheng, P. (2009). Inorg. Chem. Commun. 12, 469-472.

Saber, M. R., Abu-Youssef, M. A., Goher, M. A., Sabra, B. A., Hafez, A. K., Badr, A. M. \& Mautner, F. A. (2012). J. Mol. Struct. 1008, 1723.

Scrocco, E. \& Tomasi, J. (1978). Adv. Quantum Chem. 11, 115-193. Sheldrick, G. M. (2008). Acta Cryst. A64, 112-122.

Sinha, R. K. \& Singh, N. (2004). Trans. Met. Chem, 29, 812-820.

Soldatov, D. V., Enright, G. D. \& Ripmeester, J. A. (2004). Cryst. Growth Des. 4, 1185-1194.

Spackman, M. A. \& Jayatilaka, D. (2009). CrystEngComm, 11, 19-32.

Spackman, M. A. \& McKinnon, J. J. (2002). CrystEngComm, 4, 378392.

Spackman, M. A., McKinnon, J. J. \& Jayatilaka, D. (2008). CrystEngComm, 10, 377-388.

Spek, A. L. (2009). Acta Cryst. D65, 148-155.

Wang, C., Zhu, Z., Zhou, X., Weng, L., Shen, Q. \& Yan, Y. (2006). Inorg. Chem. Commun. 9, 1326-1330.

Yakovenko, A. A., Gallegos, J. H., Antipin, M. Y., Masunov, A. \& Timofeeva, T. V. (2011). Cryst. Growth Des. 11, 3964-3978.

Zhang, H., Wang, X., Zhang, K. \& Teo, B. K. (1999). Coord. Chem. Rev. 183, 157-195. 